\title{
O Impacto das Escolhas Contábeis na Comparabilidade das Demonstrações Financeiras de Companhias Abertas com Programa de Fidelização de Clientes ${ }^{1}$
}

\author{
The Impact of Accounting Choices in Comparison of Financial \\ Statements of Public Companies with Customer Loyalty Program
}

\section{El Impacto de las Opciones de Contabilidad en Comparación de los Estados Financieros de Empresas Públicas con Programa de Fidelización}

\begin{abstract}
Tamires Sousa Araújo
Mestranda do Programa da Pós-Graduação em Ciências Contábeis - Universidade Federal de Uberlândia Endereço: Av. João Naves de Avila, 2121, Campus Santa Mônica, Uberlândia - MG, CEP: 38.408-100, Brasil. e-mail: tamiresousa124@hotmail.com

Flaida Êmine Alves de Souza, Me.

Programa de Pós-Graduação em Ciências Contábeis - Universidade Federal de Uberlândia Endereço: Av. João Naves de Ávila, 2121 - Campus Santa Mônica, Uberlândia/MG, CEP: 38.408-100, Brasil. e-mail: flaidaemine@yahoo.com.br

Sirlei Lemes, Dr. ${ }^{\text {a }}$

Professora do Programa de Pós-Graduação em Ciências Contábeis - Universidade Federal de Uberlândia Endereço: Av. João Naves de Avila, 2121, Campus Santa Mônica, Uberlândia - MG, CEP: 38.408-100, Brasil. e-mail: sirlemes@uol.com.br
\end{abstract}

\section{RESUMO}

O objetivo desse trabalho foi identificar se as escolhas contábeis contidas na IFRIC 13 têm permitido a comparabilidade das demonstrações financeiras das companhias abertas do Brasil. Para tanto, analisou-se as demonstrações contábeis e notas explicativas de 15 entidades brasileiras listadas na Bolsa de Valores, Mercadorias e Futuros de São Paulo (BM\&FBOVESPA), nos períodos de 2010 a 2012, ou seja, desde o momento em que a IFRIC 13 tornou-se de uso obrigatório no Brasil. Para o cálculo do grau de comparabilidade dos relatórios financeiros foi utilizado o índice Herfindhal (índice H), índice utilizado para medir a comparabilidade de empresas pertencentes a um mesmo país. Para a identificação da comparabilidade entre as empresas foram observadas todas as escolhas contábeis contidas na IFRIC 13, quais sejam: (a) tipo de prêmio; (b) resgate ou conversão do prêmio; (c) operacionalização do programa; (d) fornecimento dos prêmios; (e) reconhecimento e mensuração da obrigação; e (f) fornecimento de prêmios por terceiros. Em relação à IFRIC 13, a existência de múltiplas escolhas contábeis gerou uma comparabilidade baixa entre demonstrações contábeis das entidades brasileiras. As escolhas dos gestores

\footnotetext{
1 Artigo recebido em 16.09.2014. Revisado pelos pares em 26.02.2015 (blind review). Ajustado e Aceito para publicação em 13.07.2015. Recomendado para publicação por José Ribamar Marques de Carvalho (Editor Científico). Publicado em 05.08.2015. Organização responsável UACC/CCJS/UFCG.
} 
foram muito diversificadas, o que resultou em índices de comparabilidade próximos a 0,5. Isso indica que se duas empresas brasileiras com programas de fidelidade de clientes forem selecionadas de forma aleatória, há $50 \%$ de chances que essas entidades adotem as mesmas práticas contábeis, em relação à contabilização desse programa.

Palavras-chave: IFRIC 13; Programa de fidelidade; Escolhas Contábeis; Comparabilidade.

\begin{abstract}
The aim of this study was to identify whether the accounting choices contained in IFRIC 13 have allowed the comparability of financial statements of listed companies in Brazil. To do so, it was analyzed the financial statements and notes of 15 Brazilian entities listed on the Securities, Commodities and Futures Exchange Sao Paulo (BMEFBOVESPA), the periods from 2010 to 2012, from the moment that IFRIC 13 became mandatory use in Brazil. To calculate the degree of comparability of financial reports, the Herfindhal index (H index), an index used to measure the comparability of companies belonging to the same country was used. For the identification of comparability between companies all accounting choices contained in IFRIC 13, which were observed are: (a) type of award; (b) conversion or redemption of the prize; $(c)$ implementation of the program; (d) providing the prizes; (e) recognition and measurement of the obligation; and ( $f$ ) providing prizes by third parties. Regarding IFRIC 13, the existence of multiple accounting choices generated a low comparability between financial statements of Brazilian entities. The choices of the managers were very diverse, which resulted in comparable rates of near 0.5. This indicates that two Brazilian companies with customer loyalty programs are selected at random, there is a 50\% chance that these entities adopt the same accounting practices with respect to accounting for this program.
\end{abstract}

Keywords: IFRIC 13; Loyalty program; Accounting choices; Comparability.

\title{
RESUMEN
}

El objetivo de este estudio fue identificar si las opciones contables contenidas en la IFRIC 13 han permitido a la comparabilidad de los estados financieros de las sociedades cotizadas en Brasil. Se analizaron los estados financieros y las notas de 15 entidades brasileñas que cotizan en la Superintendencia de Valores, Mercaderías y Futuros de São Paulo (BMEFBOVESPA), los períodos de 2010 a 2012, es decir, desde el momento en que la IFRIC 13 se hizo uso obligatorio en Brasil. Para calcular el grado de comparabilidad de los informes financieros, se utilizó el índice de Herfindahl (índice H), un índice que se utiliza para medir la comparabilidad de las empresas pertenecientes a un mismo país. Para la identificación de comparabilidad entre las empresas todas las opciones contables contenidas en la IFRIC 13, que se observaron son: (a) el tipo de la adjudicación; (B) la conversión o el canje de los premios; (C) la ejecución del programa; (D) la prestación de los premios; (E) el reconocimiento y la medición de la obligación; y (f) proporcionar premios por parte de terceros. En cuanto a la IFRIC 13, la existencia de múltiples opciones de contabilidad genera una baja comparabilidad entre los estados financieros de las entidades brasileñas. Las decisiones de los gerentes eran muy diversos, lo que dio como resultado tasas comparables de cerca de 0,5. Esto indica que dos empresas brasileñas con programas de fidelización de clientes son seleccionados al azar, hay un 50\% de posibilidades de que estas entidades adopten las mismas prácticas contables con respecto a la contabilización de este programa.

Palabras clave: IFRIC 13; Programa de fidelización; Opciones de Contabilidad; La comparabilidad.

\section{INTRODUÇÃO}

A contabilidade brasileira está em plena convergência com as normas internacionais de contabilidade. A adoção das International Financial Reporting Standards (IFRS), normas emitidas pelo IASB (International Accounting Standards Board), fez com que o Brasil abandonasse uma contabilidade estritamente fiscal e legalista, 
para buscar uma contabilidade mundialmente aceita, em que o seu maior foco é o usuário externo (investidor).

A internacionalização da contabilidade brasileira visa colaborar com a tendência mundial de convergência, e, acima de tudo, conquistar maior acessibilidade ao mercado global de capitais (OLIVEIRA; LEMES, 2011). A existência de um conjunto único de normas contábeis, de acordo com Oliveira e Lemes (2011, p. 155) "possibilita que investidores sejam capazes de empregar recursos financeiros em qualquer lugar do mundo sem que necessitem residir no país em que seu capital esteja alocado".

Isso ocorre porque, para que os relatórios financeiros divulgados sejam úteis à tomada de decisão do investidor, é necessário que a contabilidade entre os países tenha a mesma linguagem, ou seja, que os fatos contábeis sejam reportados de maneira similar, a fim de que sejam comparáveis. Desta forma, a comparabilidade das demonstrações contábeis das entidades torna-se fundamental, por ser a base para a tomada de decisão por parte do investidor (OLIVEIRA; LEMES, 2011).

Uma das consequências do trabalho do IASB, em busca de uma contabilidade única, foi a aprovação da IFRIC 13, interpretação técnica que orienta as entidades na contabilização de programas de fidelidade. A citada interpretação tem uma norma contábil brasileira correspondente, o Pronunciamento Técnico 30, que, além do tratamento contábil das receitas, em sua interpretação A aborda questões acerca da contabilização desses programas. Tal pronunciamento foi aprovado em 07/08/2009, pela Resolução CFC №. 1.187/09, e, antes da sua aprovação, não existiam normas que disciplinassem os programas de fidelidade no Brasil.

Para Barbosa, Sales e Paulo (2010, p. 67), a fidelização dos clientes objetiva "premiar os consumidores que utilizam de forma assídua um serviço ou produto". Um exemplo de empresas que utilizam programas de fidelização são as companhias aéreas que, por meio de um programa próprio, possibilitam ao cliente o acúmulo de milhas ou pontos a cada viagem, podendo ser trocados por descontos, passagens aéreas, serviços de hotéis e restaurantes.

De acordo com a deliberação no 597/2009 da CVM, todas as companhias abertas brasileiras que utilizam programas de fideflidade de clientes, devem, a partir dos exercícios findos em 2010, adotar o CPC 30 de maneira obrigatória. Segundo Chapple, Moerman e Rudkin (2010), a adoção da IFRIC 13 pode afetar significativamente as demonstrações financeiras das entidades que a adotam.

Entretanto, a IFRIC 13, assim como as demais normas internacionais de contabilidade emitidas pelo IASB, possuem escolhas contábeis em várias das suas etapas de contabilização. Permitem alternativas quanto ao tipo e fornecimento de prêmio, quanto à forma de resgate, quanto à operacionalização do programa, quanto ao reconhecimento da receita, dentre outros. 
Assim, ante o exposto, este estudo buscou responder ao seguinte questionamento: Qual é o grau de comparabilidade das demonstrações contábeis das companhias abertas brasileiras, em relação ao programa de fidelização de clientes? Nesse sentido, o objetivo desse trabalho é identificar se as escolhas contábeis contidas na IFRIC 13, têm permitido a comparabilidade das demonstrações financeiras das companhias abertas do Brasil.

Para tanto, foram analisadas as demonstrações contábeis e notas explicativas de 15 entidades brasileiras listadas na Bolsa de Valores, Mercadorias e Futuros de São Paulo (BM\&FBOVESPA), para os períodos de 2010 a2012, ou seja, desde o momento em que a IFRIC 13 tornou-se de uso obrigatório no Brasil. Para o cálculo do grau de comparabilidade dos relatórios financeiros, foi utilizado o índice Herfindhal (índice $\mathrm{H}$ ), que, de acordo com Van Der Tas (1988), deve ser utilizado quando se deseja medir a comparabilidade de empresas pertencentes a um mesmo país.

Espera-se que este estudo contribua com a prática contábil, ao demonstrar aos usuários se as demonstrações contábeis, no que diz respeito ao programa de fidelidade de clientes, são comparáveis entre entidades e entre períodos, o que facilitaria o processo de tomada de decisões. Para a literatura internacional, almeja-se contribuir com os estudos sobre escolhas contábeis, cuja compreensão sobre os determinantes e implicações das escolhas contábeis continua limitada(FIELDS; LYS; VINCENT, 2001; FRANCIS, 2001). Nessas obras são apontadas as limitações e o progresso limitado nas pesquisas sobre escolhas contábeis. Silva, Martins e Lemes (2014), a partir de uma revisão da literatura sobre o tema, identificam poucos avanços para solucionar os problemas apontados por Fields, Lys e Vincent (2001) e Francis (2001), indicando um vasto campo de pesquisa sobre o impacto das IFRS no Brasil, concernentes às escolhas contábeis. Ademais, são necessárias mais estudos que investiguem as demonstrações contábeis e provoquem discussões sobre o conceito de comparabilidade, que ainda se encontra em sua fase de infância (TAPLIN, 2011). Para os elaboradores das normas internacionais, esta pesquisa almeja colaborar ao identificar, no que tange à IFRIC 13, se o seu objetivo de comparabilidade tem sido alcançado.

Além desta introdução, o artigo está estruturado em quatro sessões. Na segunda sessão, é apresentado a Fundamentação Teórica, e, em seguida, o Método de Pesquisa. Na sessão quatro estão descritas a Análise dos Dados e os Resultados Obtidos. Por último, são ilustradas as Considerações Finais.

\section{FUNDAMENTAÇÃO TEÓRICA}

A seguir uma revisão teórica sobre programas de fidelização de clientes e sua legislação por meio da IFRIC 13, seguido da apresentação de algumas pesquisas já realizadas sobre o tema. 


\title{
2.1 PROGRAMA DE FIDELIDADE
}

De acordo com o CPC 30 (2009, p. 22), os programas de fidelidade são utilizados pelas empresas como estratégia para aumentar o consumo de seus produtos e serviços:

\begin{abstract}
Os programas de fidelidade com o cliente são usados pelas entidades como meio de dar aos seus clientes incentivos para consumir seus produtos ou serviços. Se um cliente consome produtos ou serviços, a entidade em contrapartida concede ao cliente créditos em prêmio (frequentemente descritos como "pontos", "milhagens", etc.).
\end{abstract}

Quando um cliente adquire um produto ou serviço, a empresa o pontua ou oferece vantagens para sua recuperação posterior, ou acumulação de créditos para compras futuras, o que tornaria esse cliente fiel. Para Ernst \& YongTerco e Fipecafi (2010), a fidelização do cliente faz parte integral dos negócios. Em um mercado em que o cliente é o foco, sua participação assídua no consumo dos produtos gerados pela empresa é a base de qualquer negócio.

O programa de fidelidade é uma maneira eficiente de agradar os clientes com possíveis gratificações (BARBOSA, SALES, PAULO, 2010). Segundo Barbosa, Sales e Paulo, (2010, p. 66), "não só os usuários de cada produto e serviço se sentem valorizados, como tendem a mudar seu consumo de forma a se beneficiar com as premiações". Essa fidelização acontece mais frequentemente em companhias aéreas, cartões de crédito, lojas de conveniências.

Os programas de fidelidade de clientes, como dito em momento anterior, são tratados pela IFRIC 13, que, no Brasil, corresponde à Interpretação $\mathrm{A}$, disposta no Pronunciamento Técnico CPC 30. Em conformidade com o disposto neste pronunciamento, os créditos em prêmios devem ser contabilizados pelos seus valores justos, e de maneira separada da transação de venda que lhe deu origem.

Barbosa, Sales e Paulo (2010, p. 69) afirmam que:

a interpretação IFRIC 13 acrescenta que o montante pelo qual os créditos de prêmio de fidelidade de clientes poderiam ser vendidos separadamente será o seu valor justo e deve levar em consideração: (a) o valor justo dos prêmios que seriam oferecidos aos clientes que não obtiveram créditos de prêmio da venda inicial; e (b) a proporção dos créditos de prêmio que não se espera que seja resgatada pelos clientes. Além disso, se os clientes puderem escolher entre diferentes prêmios, o valor justo dos créditos de prêmio deve refletir o valor justo da série de prêmios disponíveis, ponderado na proporção da frequência com a qual se espera que cada prêmio seja selecionado.

Nesse sentido, a IFRIC 13 orienta que para se contabilizar o programa de fidelidade é necessário calcular os devidos créditos a serem "presenteados" aos 
clientes, pelo seu valor justo, ou seja, pelo preço de mercado cotado por meio do qual eles podem ser resgatados. Se não houver preço de mercado, "o valor justo deve ser mensurado utilizando outra técnica de avaliação" (CPC 30, p. 25).

O CPC 30, no item 13, define que, caso uma receita corresponda a prestações de serviços posteriores, os valores são reconhecidos e diferidos como receita até a execução do serviço. O referido item reflete, diretamente, no programa de fidelidade de clientes. O serviço a ser prestado, posteriormente, ao cliente, para fins de reconhecimento, deve ser considerado como uma receita no momento da venda do serviço principal. De outra forma, aquilo que o cliente adquire para obter o crédito deve ser contabilizado pelo seu valor justo, como afirmado na norma internacional, (ARAÚJO; LEMES, 2012).

Lemes e Carvalho (2010, p. 103) orientam que a IFRIC 13 mostra como reconhecer as receitas decorrentes de créditos referentes a programa de fidelidade de clientes:

a) a entidade deverá aplicar a IAS 18 e contabilizar os créditos (pontos) como um item separado (no passivo) da receita da transação inicial na qual eles foram concedidos (a venda ou a prestação de serviço inicial);

b) o valor justo do pagamento recebido ou a receber referente à venda ou à prestação de serviço inicial deverá ser alocado (distribuído) entre o crédito (pontos) concedido ao cliente e a receita da venda ou da prestação de serviço, e

c) o pagamento alocado ao crédito (pontos) deverá ser mensurado ao valor justo, ou seja, o valor pelo qual tal crédito poderia ser negociado separadamente.

As informações a serem divulgadas em relação ao crédito do programa de fidelidade, referente ao seu método utilizado, a forma de contabilização, e qualquer informação adicional deve ser divulgado nas Notas Explicativas. De acordo com Iudicibus et al. (2009, p.54), há três incisos de grande importância para a orientação da elaboração das Notas Explicativas:

I - apresentar informações sobre a base de preparação das demonstrações financeiras e das praticas contábeis específicas selecionadas e aplicadas para negócios e eventos significativos;

II - divulgar as informações exigidas pelas práticas contábeis adotadas no Brasil que não estejam apresentadas em nenhuma outra parte das demonstrações financeiras;

III - fornecer informações adicionais não indicadas nas próprias demonstrações financeiras e consideradas necessárias para uma apresentação adequada; 
Nesse sentido, as Notas Explicativas têm papel relevante para classificar e complementar as informações contidas nas demonstrações contábeis, bem como para esclarecimentos quanto à adoção da IFRIC 13 e o CPC 30, (ARAÚJO; LEMES, 2012). A forma de evidenciação dessas informações também é importante. De acordo com o CPC 30 (2009, p. 12), item 35 da divulgação, a empresa que tem programa de fidelidade deverá divulgar:

(a) as políticas contábeis adotadas para o reconhecimento das receitas, incluindo os métodos adotados para determinar à fase de execução de transações que envolvam a prestação de serviço;

(b) o montante de cada categoria significativa de receita reconhecida durante o período, incluindo as receitas provenientes de:

(i) venda de bens;

(ii) prestação de serviços;

(iii) juros;

(iv) royalties;

(v) dividendos;

(c) o montante de receitas provenientes de troca de bens ou serviços incluídos em cada categoria significativa de receita; $\mathrm{e}$

(d) a conciliação entre a receita divulgada na demonstração do resultado e a registrada para fins tributáveis, conforme itens $8 \mathrm{~A}$ e $8 \mathrm{~B}$.

Como se pode notar, a intenção da IFRIC 13, corroborando a tendência das outras normas internacionais, é de proporcionar informações de melhor qualidade e transparência aos usuários externos, o que reflete em uma divulgação das informações econômico-financeiras de forma completa.

\subsection{COMPARABILIDADE VERSUS ESCOLHAS CONTÁBEIS}

Segundo Cairns et al. (2010, p. 2) "um dos principais objetivos da adoção das IFRS é melhorar a comparabilidade internacional dos relatórios financeiros". É fazer com que os demonstrativos contábeis, independente da empresa, do país, ou do ano observado, possuam a mesma base normativa e, em consequência, sejam comparáveis.

Isso ocorre em virtude da comparabilidade ter o poder de dar suporte ao usuário, capacitando-o a comparar as demonstrações contábeis de entidades distintas, observando os anos, identificando o seu desempenho (IUDÍCIBUS, MARION, 2006).

De acordo com o CPC 00 (2011) norma contábil brasileira equivalente à norma internacional The Conceptual Framework for Financial Reporting, emitida pelo IASB, para que a informação contábil-financeira possa ser útil ao usuário, ela precisa ser útil, relevante e representar com fidedignidade a situação da entidade. Ademais, para que a utilidade dessa informação seja melhorada, é necessário que ela obedeça às 
características qualitativas de melhoria: comparabilidade, verificabilidade, tempestividade e compreensibilidade.

Nesse sentido, pode-se definir comparabilidade como "a característica qualitativa que permite que os usuários identifiquem e compreendam similaridades dos itens e diferenças entre eles" (CPC 00, 2011, item QC 21). Isso significa que a informação será mais útil, quando puder ser comparada com informação similar sobre outras entidades, ou sobre a mesma entidade, em outros períodos de tempo.

Para que uma informação seja comparável, portanto, "coisas iguais precisam parecer iguais e coisas diferentes precisam parecer diferentes" (CPC 00, 2011, item QC 23). Todavia, apesar de um fenômeno econômico puder ser representado com fidedignidade de inúmeras maneiras, o uso discricionário das escolhas contábeis para o mesmo fenômeno, podem diminuir a comparabilidade (CPC 00, 2011).

Segundo Fields, Lyz e Vicent (2001) uma escolha contábil é qualquer decisão que tem o poder de influenciar os resultados das demonstrações financeiras. Por esse motivo, o IASB tem buscado fazer melhorias em suas normas internacionais emitidas, a fim de reduzir as escolhas contábeis existentes, ou eliminá-las (CAIRNS et. al., 2010).

Murcia e Wuerges (2011) apontam que tanto a elaboração, quanto a divulgação das demonstrações contábeis envolvem julgamentos, em virtude das escolhas contábeis existentes. Estas geram a capacidade de influenciar o resultado da companhia (PRADO, BATISTA, BONOLI, 2012), o que, de certa forma, reflete na comparabilidade e diminui a utilidade da informação reportada.

\subsection{PESQUISAS SOBRE O TEMA}

A literatura nacional e internacional ainda é relativamente recente sobre o tema. A causa disso é o fato de que o tratamento contábil da prática de fidelização de clientes por meio de prêmios também é relativamente recente, pois a IFRIC 13 foi aprovada em 2007, entrando em vigor em 2008. Outra provável causa para a literatura incipiente sobre o tema se refere ao fato de algumas empresas com programas pouco representativos e/ou com baixo percentual de resgate pelos clientes tratarem todo o valor da venda do produto inicial como receita, sem diferimento da receita futura. Nesse caso, essas empresas podem estar se amparando na materialidade da informação.

Barbosa, Sales, Paulo (2010) analisaram o impacto da adoção da IFRIC 13 nas demonstrações contábeis das companhias aéreas GOL e TAM, concluindo que "o impacto da IFRIC 13 nas demonstrações contábeis do setor de transporte aéreo brasileiro é significativo, pois se alterou a composição patrimonial, o resultado e vários indicadores financeiros das companhias". 
Chapple, Moerman, Rudkin (2010) apresentaram os pontos de vista e os desafios de uma série de profissionais de contabilidade com relação à preparação da introdução de uma abordagem padronizada para a contabilização de Programas de Fidelização de Clientes, fazendo uma análise da empresa aérea Airliners, tendo verificado que a IFRIC 13 altera, significativamente, as demonstrações da empresa. Gujarathy e Yezegel (2014a) fazem uma análise crítica do impacto da IFRIC 13 por meio de um estudo de caso de uma empresa aérea. Gujarathy e Yezegel (2014b) discutem o caso apontando as diferenças contábeis no reconhecimento dos programas de fidelização entre os US GAAP e as IFRS.

Observa-se que as pesquisas destacadas estudaram o impacto da adoção da IFRIC 13 em companhias aéreas, identificando que houve mudanças significativas. A presente pesquisa tem o potencial de ampliar os estudos referentes a aspectos de evidenciação do setor aéreo, além de contemplar o tratamento das receitas de programas de fidelização de clientes de outros segmentos.

A literatura contábil sobre escolhas contábeis é ampla com relação a mensuração e reconhecimento de itens específicos como ativos intangíveis (SOUZA; SILVA; COSTA, 2013; TUDOR; DRAGU, 2010), propriedades para investimento (MULLER; RIEDL; SELLHORN, 2008; TAPLIN; YUAN; BROWN, 2014), valor justo (DEMARIA; DUFOUR, 2007; CAIRNS et al., 2010); ativo imobilizado (MURCIA et al., 2013; LEMES; COSTA; MARTINS, 2014) e ativo diferido (LORENCINI; COSTA, 2012), entre outras novas práticas introduzidas pela convergência às IFRS. Este pesquisa buscou contribuir com a avaliação do impacto das novas regras de reconhecimento dos programas de fidelização, tema ainda relativamente pouco explorado na literatura, de forma a se ampliar a dimensão dos estudos sobre as escolhas contábeis permitidas pelo IASB.

\section{MÉTODO DE PESQUISA}

A amostra da pesquisa foi composta por 15 companhias abertas, que representam a totalidade das entidades que possuíam programa de fidelização de clientes, em conformidade com a IFRIC 13, nos três períodos estudados. Os anos de 2010 a 2012 foram escolhidos, em virtude de que as companhias abertas brasileiras foram obrigadas a adotar as IFRS a partir do exercício findo em 2010 (Instrução da CVM 457/2007). Assim, para se avaliar a comparabilidade dos relatórios financeiros, entendeu-se adequado considerar os últimos exercícios sociais divulgados, a contar desta data. A identificação das entidades foi realizada por meio do site da BM\&FBOVESPA e a busca das demonstrações contábeis se deu pelo site da Comissão de Valores Mobiliários (CVM). 
Em 2013, foram identificadas 529 empresas listadas na BM\&FBOVESPA, em que, destas, 513 entidades não apresentaram programa de fidelização de clientes em nenhum, ou em algum dos períodos analisados. Das 16 entidades que apresentaram programa de fidelização em conformidade com a IFRIC 13, uma empresa foi excluída da amostra (Banco Patagônia S.A.), por não publicar as demonstrações contábeis de 2010 e de 2011, o que impossibilitou a análise de suas notas explicativas, e, em consequência, de suas escolhas contábeis.

Para a análise das escolhas contábeis da empresa TAM S.A., surgiram algumas peculiaridades, em virtude da fusão ocorrida entre essa empresa e a LAN AIRLINES S.A., que, em 2012, deu origem à companhia aberta Latam Airlines Group S.A. Em virtude dessa fusão, para a análise das escolhas contábeis dessa entidade, recorreu-se às notas explicativas publicadas pela TAM S.A. em 2010 e 2011, e às notas explicativas publicadas pela Latam Airlines Group S.A., em 2012.

A fim de permitir uma visão geral dos impactos da mudança da IFRIC 13 nas demonstrações contábeis das empresas que compõem a amostra, foi realizada uma análise dos relatórios consolidados dessas entidades, no ano de 2009, e na reapresentação do mesmo, no ano de 2010, estabelecendo uma comparação entre as duas divulgações. As empresas utilizadas na amostra são evidenciadas na Tabela 1, bem como o faturamento do ano de 2009, e a reapresentação de tal informação em 2010.

Tabela 1 - Valor da Receita bruta, em milhares de reais

\begin{tabular}{|c|c|c|c|c|}
\hline Empresa & $\begin{array}{c}\text { Faturamento } \\
2009\end{array}$ & $\begin{array}{l}\text { Faturamento } \\
2009 \text { ref. } 2010\end{array}$ & Variação \% & $\begin{array}{c}\text { Nível de } \\
\text { Governança }\end{array}$ \\
\hline B2W - Companhia Digital & 1.063 .933 & 1.062 .545 & $-0.130 \%$ & NM \\
\hline Banco do Brasil S.A & 18.232 .859 & 28.305 .864 & $55.246 \%$ & NM \\
\hline $\begin{array}{l}\text { Cia Brasileira de } \\
\text { Distribuição -P.ACUCAR- }\end{array}$ & 5.760 .377 & 5.698 .952 & $-1.066 \%$ & N1 \\
\hline Cielo S. A & 2.508 .609 & 2.508 .609 & $0.000 \%$ & NM \\
\hline $\begin{array}{l}\text { Gol Linhas Aéreas } \\
\text { Inteligentes S.A }\end{array}$ & 1.295 .073 & 1.327 .770 & $2.525 \%$ & N2 \\
\hline Jereissati Patricipações & 2.698 .995 & 2.744 .838 & $1.699 \%$ & - \\
\hline $\begin{array}{l}\text { TAM S. A (Latam Airlines } \\
\text { Group S.A.) }\end{array}$ & 2.651 .910 & 2.549 .743 & $-3.853 \%$ & DR3 \\
\hline LF TEL S.A. & 2.551 .813 & 2.583 .580 & $1.245 \%$ & - \\
\hline Multiplus S.A. & 0 & 0 & $0.000 \%$ & NM \\
\hline Oi S.A. & 4.972 .964 & 5.155 .669 & $3.674 \%$ & N1 \\
\hline Porto Seguro S.A. & 0 & 0 & $0.000 \%$ & NM \\
\hline $\begin{array}{l}\text { Saraiva S.A. Livreiros } \\
\text { Editores }\end{array}$ & 560.565 & 558.029 & $-0.452 \%$ & $\mathrm{~N} 2$ \\
\hline Telefônica Brasil S.A. & 6.840 .267 & 6.714 .205 & $-1.843 \%$ & - \\
\hline Telemar Participações S.A. & 12.665 .805 & 11.488 .386 & $-9.296 \%$ & - \\
\hline Ultrapar Participações S.A & 2.703 .905 & 2.653 .494 & $-1.864 \%$ & NM \\
\hline
\end{tabular}

Fonte: Elaborado pelos autores. 
Selecionadas as entidades que compuseram a amostra e reunidas suas demonstrações financeiras e notas explicativas, partiu-se para a identificação de todas as escolhas contábeis existentes na IFRIC 13. Foram encontradas as seguintes opções na norma: (a) tipo de prêmio; (b) resgate ou conversão do prêmio; (c) operacionalização do programa; (d) fornecimento dos prêmios; (e) reconhecimento e mensuração da obrigação; e (f) fornecimento de prêmios por terceiros.

A análise foi feita para cada uma das escolhas contábeis mencionadas acima, e, por consequência, foi determinando o número de métodos contábeis utilizados, os não utilizados e os não mencionados pelas entidades. Quando a entidade não divulgava a informação pesquisada, essa "não divulgação" foi tratada como uma escolha contábil, e, portanto, não foi excluída do cálculo da comparabilidade.

Posteriormente, calcularam-se as frequências relativas e o índice de comparabilidade para cada escolha, para, ao final, mensurar a comparabilidade das demonstrações financeiras em relação aos programas de fidelidade, por meio da média desses índices. O grau de comparabilidade foi medido por meio do índice $\mathrm{H}$, cuja equação é dada por Van Der Tas (2008, p. 159):

$$
H=\sum_{i=1}^{n} p i^{2}(1)
$$

Onde:

$H$ : índice Herfindahl;

n: número de alternativas de métodos contábeis disponíveis;

pi:frequência relativa em correlação com o método contábil $i$, que varia de 1 a $n$.

Quanto à análise do índice, este varia de 0 a 1, em que 1 significa um grau de comparabilidade máximo para este elemento (isto é, todas as empresas utilizam o mesmo método contábil) e 0 significa que não há comparabilidade (TUDOR, DRAGU, 2010). Trata-se de um índice utilizado para se mensurar a comparabilidade de empresas de um mesmo país, em virtude de se considerar todas as empresas com pesos iguais (VAN DER TAS, 1988). A limitação desse índice é a impossibilidade de se calcular a comparabilidade entre países, ou de se calcular a comparabilidade quando há múltiplas escolhas contábeis. Posto que essas duas questões não são objeto de investigação nesta pesquisa, apesar de existirem outros índices de comparabilidade (C, I e T), o índice H é o indicador adequado para se medir a comparabilidade dos relatórios contábeis das empresas.

\section{ANÁliSE E DISCUSSÃO DOS RESULTADOS}


Partindo-se para a análise do grau de comparabilidade das demonstrações financeiras em relação aos programas de fidelização de clientes, primeiro identificouse as escolhas contábeis dos gestores, ano a ano, em relação ao disposto na IFRIC13. Posteriormente, calculou-se o índice $\mathrm{H}$ para cada etapa, e, em seguida, foi feita a média desses indicadores.

Pela apreciação da Tabela 2, percebe-se que as entidades brasileiras apresentaram uma comparabilidade próxima a 0,5 nos três períodos analisados. Ao se observar o ano de 2012, por exemplo, se duas empresas que possuem programas de fidelidade de clientes forem selecionadas de forma aleatória, há 48,7\% de chance que essas entidades tenham adotado as mesmas práticas contábeis, em relação à contabilização desse programa.

Em 2010, a comparabilidade de 41,7\% entre as demonstrações financeiras das entidades com programas de fidelidade pode ter sido fruto da não divulgação das informações obrigatórias, considerada nesse trabalho como uma escolha contábil da entidade, e, portanto, não excluída do cálculo do índice. Para 2011 e 2012, percebeu-se uma maior divulgação das informações obrigatórias por parte das entidades, o que ocasionou um aumento na comparabilidade dos relatórios das entidades, porém, nada significativo.

Quanto à análise das escolhas contábeis das companhias abertas brasileiras, tem-se que, a maioria das entidades $(40 \%, 73,3 \%$ e 66,7\% para 2010, 2011 e 2012, respectivamente) escolheram os "pontos" como tipo de prêmio para distribuir aos seus clientes quando adquirem seus produtos ou serviços.

Tabela 2 - Escolhas Contábeis em Programas de Fidelidade (IFRIC 13)

\begin{tabular}{|c|c|c|c|c|c|c|c|c|c|}
\hline \multirow{2}{*}{$\begin{array}{c}\text { ESCOLHAS CONTÁBEIS - IFRIC } 13 \\
\text { PROGRAMA DE FIDELIDADE }\end{array}$} & \multicolumn{3}{|c|}{ № de Empresas } & \multicolumn{3}{|c|}{$\begin{array}{c}\text { Frequência } \\
\text { Rolativa }\end{array}$} & \multicolumn{3}{|c|}{ Índice $\mathbf{H}$} \\
\hline & 2010 & 2011 & 2012 & 2010 & 2011 & 2012 & 2010 & 2011 & 2012 \\
\hline Tipo de Prêmio & 15 & 15 & 15 & 1.000 & 1.000 & 1.000 & & & \\
\hline a) Pontos & 6 & 11 & 10 & 0.400 & 0.733 & 0.667 & & & \\
\hline b) Milhagens & 1 & 1 & 1 & 0.067 & 0.067 & 0.067 & & & \\
\hline c) Créditos & 1 & 1 & 1 & 0.067 & 0.067 & 0.067 & 0.333 & 0.556 & 0.476 \\
\hline d) Outro & 0 & 0 & 0 & 0.000 & 0.000 & 0.000 & & & \\
\hline e) Mais de um prêmio & 1 & 1 & 2 & 0.067 & 0.067 & 0.133 & & & \\
\hline f) Não divulga & 6 & 1 & 1 & 0.400 & 0.067 & 0.067 & & & \\
\hline Resgate/Conversão & 15 & 15 & 15 & 1.000 & 1.000 & 1.000 & & & \\
\hline a) Produtos ou serviços gratuitos & 7 & 11 & 7 & 0.467 & 0.733 & 0.467 & & & \\
\hline b) Desconto & 2 & 2 & 2 & 0.133 & 0.133 & 0.133 & 0.396 & 0.564 & 0.351 \\
\hline c) Ambos & 0 & 1 & 5 & 0.000 & 0.067 & 0.333 & & & \\
\hline d) Não divulga & 6 & 1 & 1 & 0.400 & 0.067 & 0.067 & & & \\
\hline Operação do Programa & 15 & 15 & 15 & 1.000 & 1.000 & 1.000 & & & \\
\hline a) Por conta própria & 7 & 12 & 12 & 0.467 & 0.800 & 0.800 & & & \\
\hline b) Por conta de terceiros & 1 & 1 & 1 & 0.067 & 0.067 & 0.067 & 0.440 & 0.662 & 0.662 \\
\hline c) Ambos & 0 & 0 & 0 & 0.000 & 0.000 & 0.000 & & & \\
\hline d) Não divulga & 7 & 2 & 2 & 0.467 & 0.133 & 0.133 & & & \\
\hline
\end{tabular}




\begin{tabular}{lccccccccc}
\hline Fornecimento dos Prêmios & $\mathbf{1 5}$ & $\mathbf{1 5}$ & $\mathbf{1 5}$ & $\mathbf{1 . 0 0 0}$ & $\mathbf{1 . 0 0 0}$ & $\mathbf{1 . 0 0 0}$ & & & \\
a) Produtos/serviços oferecidos pela & 4 & 5 & 5 & 0.267 & 0.333 & 0.333 & & & \\
b) Produtos/serviços oferecidos por terceiro & 0 & 0 & 0 & 0.000 & 0.000 & 0.000 & 0.360 & 0.413 & 0.413 \\
c) Ambos & 4 & 8 & 8 & 0.267 & 0.533 & 0.533 & & & \\
d) Não divulga & 7 & 2 & 2 & 0.467 & 0.133 & 0.133 & & & \\
\hline Obrigação Reconhecida e Mensurada & $\mathbf{1 5}$ & $\mathbf{1 5}$ & $\mathbf{1 5}$ & $\mathbf{1 . 0 0 0}$ & $\mathbf{1 . 0 0 0}$ & $\mathbf{1 . 0 0 0}$ & & & \\
a) Diferimento do reconhecimento da receita & 5 & 10 & 10 & 0.333 & 0.667 & 0.667 & 0.369 & 0.502 & 0.502 \\
b) Constituição de provisão para custos & 3 & 3 & 3 & 0.200 & 0.200 & 0.200 & & & \\
c) Não divulga & 7 & 2 & 2 & 0.467 & 0.133 & 0.133 & & \\
\hline Fornecimento de Prêmios por Terceiros & $\mathbf{1 5}$ & $\mathbf{1 5}$ & $\mathbf{1 5}$ & $\mathbf{1 . 0 0 0}$ & $\mathbf{1 . 0 0 0}$ & $\mathbf{1 . 0 0 0}$ & & \\
a) Cobra a contraprestação em nome de & 0 & 0 & 0 & 0.000 & 0.000 & 0.000 & & \\
b) Cobra a contraprestação por sua conta & 3 & 7 & 6 & 0.273 & 0.700 & 0.600 & 0.603 & 0.580 & 0.520 \\
c) Não divulga & 8 & 3 & 4 & 0.727 & 0.300 & 0.400 & & & \\
d) Não se aplica & 4 & 5 & 5 & & & & & & \\
\hline
\end{tabular}

GRAU DE COMPARABILIDADE

$\begin{array}{lll}0.417 & 0.546 & 0.487\end{array}$

Fonte: Dados da pesquisa.

Em relação ao resgate desses pontos, verificou-se que a opção mais escolhida pelas entidades foi o fornecimento de produtos ou serviços gratuitos. Em 2011, por exemplo, 73,3\% das empresas escolheram essa modalidade para resgate de pontos pelos clientes. Em 2012, constatou-se uma maior diversidade entre as escolhas contábeis dos gestores, o que refletiu na menor comparabilidade nesse quesito, se comparada aos demais períodos.

Ao se analisar a operação do programa, notou-se que das entidades que evidenciaram tais informações, apenas uma tem o seu programa regulado por terceiro. No que tange ao fornecimento dos prêmios, nenhuma entidade fornece prêmios exclusivamente por terceiros. As entidades se diversificam em fornecer os prêmios por conta própria e por terceiro, a escolha do cliente (26,7, 53,3\% e 53,3\%, em 2010, 2011 e 2012 , nesta ordem), bem como exclusivamente por conta própria $(26,7 \%, 33,3 \%$ e $33,3 \%$, respectivamente). Quando os prêmios são oferecidos por terceiros, das entidades que divulgam tais informações, todas cobram a contraprestação por sua conta própria, ou seja, mensura a sua receita pelo valor bruto, reconhecendo a receita quando cumprida a obrigação em relação aos prêmios.

Por fim, no que tange à obrigação reconhecida e mensurada, das entidades que divulgam essas informações, a maioria $(62,5 \%, 76,92 \%$ e $76,92 \%$, respectivamente) optou por alocar parte da contraprestação recebida ou a receber com o diferimento do reconhecimento da receita.

\section{CONSIDERAÇÕES FINAIS}

A presente pesquisa teve o objetivo de identificar se as escolhas contábeis contidas na IFRIC 13 têm permitido a comparabilidade das demonstrações financeiras das companhias abertas do Brasil. Para tanto, foram observadas 15 entidades 
brasileiras listadas na BM\&FBOVESPA, no horizonte temporal de 2010 a 2012. As empresas analisadas representam o número total de empresas que utilizaram o programa de fidelização de clientes, em conformidade com a IFRIC 13, nos três períodos analisados.

Com a finalidade de se calcular a comparabilidade dos relatórios financeiros, foram identificadas seis escolhas contábeis na IFRIC 13: (a) tipo de prêmio; (b) resgate ou conversão do prêmio; (c) operacionalização do programa; (d) fornecimento dos prêmios; (e) reconhecimento e mensuração da obrigação; e (f) fornecimento de prêmios por terceiros. As informações não divulgadas foram tratadas como uma escolha contábil da entidade, e, portanto, não foram excluídas do cálculo da comparabilidade.

Como resultados do estudo constatou-se que, em relação à IFRIC 13, a existência de múltiplas escolhas contábeis gerou uma comparabilidade baixa das demonstrações contábeis das entidades brasileiras. As escolhas dos gestores foram muito diversificadas, o que resultou em índices de comparabilidade próximos a 0,5. Um índice de 0,417, como o encontrado em 2010, por exemplo, indica que se duas entidades que possuem programas de fidelização de clientes forem aleatoriamente selecionadas, há $41,7 \%$ de chance de que elas optem pelos mesmos métodos contábeis em relação a esse programa.

Esses achados corroboram os resultados da pesquisa de Souza, Silva e Costa (2013), que constataram que os índices de comparabilidade são mais baixos quando se têm um maior número de escolhas contábeis disponíveis. De maneira similar, os resultados dessa pesquisa vão ao encontro das conclusões de Haller e Wehrfritz (2013), que trouxeram que a eliminação ou redução das escolhas contábeis podem reduzir as diferenças e promover a comparabilidade. Segundo eles, os relatórios financeiros continuarão tendo diferenças, mesmo com a adoção das IFRS.

De uma maneira geral, verificou-se que a maioria das empresas distribuem pontos aos seus clientes quando adquirem seus produtos ou serviços. Constatou-se, também, que o resgate desses pontos, em sua maioria, refere-se ao fornecimento de produtos ou serviços gratuitos. A operacionalização do programa é feita, geralmente, pela própria empresa e nenhuma entidade fornece prêmio exclusivamente por terceiro: ou ela fornece por conta própria, ou o cliente escolhe se resgata os prêmios ou serviços na própria companhia ou em estabelecimento autorizado (terceiro). Caso o cliente opte por resgatar o prêmio por terceiro, as companhias, comumente, cobram essas contraprestações em nome próprio.

Quanto ao reconhecimento da obrigação referente ao prêmio, a maioria das empresas opta pela alocação da contraprestação com o diferimento do reconhecimento da receita. Poucas entidades optam pela constituição da provisão para custos futuros.

Cabe salientar, no entanto, que os resultados encontrados nesta pesquisa quedaram-se, de certa forma, prejudicados pelo elevado número de entidades que não 
divulgaram as informações obrigatórias acerca do seu programa de fidelização. Com o passar dos anos, percebeu-se que a divulgação tem aumentado, o que permitiu uma melhor análise dos dados aqui apresentados. Essa majoração no disclosure pode ter sido fruto: ou de uma maior fiscalização por parte dos auditores, ou de uma maior consciência e experiência com as normas por parte dos elaboradores dos relatórios financeiros, ou de uma maior exigência por parte dos usuários externos. Nesse sentido, a baixa evidenciação foi considerada como uma limitação deste estudo.

Essa pesquisa complementou estudos anteriores sobre comparabilidade e escolhas contábeis (CAIRNS et. al., 2010, HALLER; WEHRFRITZ, 2013, SOUZA; SILVA; COSTA, 2013) e buscou contribuir com a literatura internacional ao indicar o grau de comparabilidade das demonstrações contábeis no que diz respeito à IFRIC 13. Para os normatizadores, essa pesquisa trouxe evidências acerca da diversidade de práticas contábeis adotadas pelos elaboradores dos relatórios financeiros em relação aos programas de fidelidade, o que resultou em uma comparabilidade próxima a 0,5. Ademais, intentou-se sinalizar, por meio da análise ao longo do tempo, que essa comparabilidade não tem melhorado com o passar dos anos, o que subsidia futuras decisões quanto a alterações nessa norma.

Como futuras pesquisas, sugere-se a observação dos exercícios seguintes aos aqui analisados, visando identificar se o comportamento da comparabilidade se mantém ou é alterada com uma melhor prática de evidenciação ou experiência por parte das entidades. Sugere-se, também, analisar companhias de outros países, visando identificar, de forma ampla, se os resultados aqui apresentados são similares aos de outras regiões; verificar possíveis variáveis explicativas para a escolha contábil dos gestores.

\section{REFÊRENCIAS}

ARAÚJO, T. S.; LEMES, S. Impacto da IFRIC 13 nas Demonstrações Contábeis de Companhias que Possuem Programa de Fidelização de Clientes. In: SIMPÓSIO DE EXCELÊNCIA EM GESTÃO E TECNOLOGIA, 9, 2012, Resende. Anais... Rio de Janeiro: $2012 . \quad$ SEGET, Disponível em: <http://www.aedb.br/seget/artigos12/31416266.pdf>

BARBOSA, G. C.; SALES, I. C. H.; PAULO, E. Impacto da adoção da IFRIC 13 na contabilização de programas de passageiros freqüentes. Revista Eletrônica de Ciências Administrativa (RECADM), v. 10, n. 2, p. 64-79, jul./dez. 2011. Disponível em:<http://revistas.facecla.com.br/index.php/recadm/article/view/854/562>. Acesso em março de 2014. 
BM\&FBOVESPA. Empresas Listadas. Disponível em: $<$ http://www.bmfbovespa.com.br/Cias-Listadas/Empresaslistadas/BuscaEmpresaListada.aspx?idioma=pt-br>.Acessojaneiro de 2014.

CAIRNS, D.; MASSOUDI, D.; TAPLIN, R.; TARCA, A. IFRS fair value measurement and

accounting policy choice in the United Kingdom and Australia. The British Accounting

Review, v. xxx, p. 1-21, 2010.

CHAPPLE, S.; MOERMAN, L.; RUDKIN, K. IFRIC 13: accounting for "customer loyalty programmes". Accounting Research Journal, v. 23, n. 2. p. 124-145, 2010.

COMITÊ DE PRONUNCIAMENTOS CONTÁBEIS. CPC 00 - Pronunciamento Conceitual Básico (R1). 2011. Disponível em: <www.cpc.org.br/pdf/cpc00_r1.pdf>. Acesso em: 27 jan. 2014.

COMITÊ DE PRONUNCIAMENTOS CONTÁBEIS. CPC 30. Pronunciamento Técnico $\quad$ CPC $\quad 30 \quad$ R1- $\quad$ Receitas. Disponível em: <http://www.cpc.org.br/pdf/CPC\%2030\%20(R1)\%2031102012-limpo\%20final.pdf >. Acesso em março de 2014.

CVM. Comissão de Valores Mobiliários. DELIBERAÇÃO CVM № 597. Aprova o pronunciamento técnico CPC 30 do Comitê de Pronunciamentos Contábeis, que trata de receitas. Comunicado ao Mercado, 15 de setembro de 2009.

DEMARIA, S.; DUFOUR, D. First time adoption of IFRS, Fair value option, Conservatism: Evidences from French listed companies. EAA, 2007. Disponível em: $<$ http://hal.archives-

ouvertes.fr/docs/00/26/61/89/PDF/First_adoption_and_fair_value_Demaria_Dufour.p df $>$. Acesso em: 03/04/2014.

ERNST\&YOUNG TERCO e FIPECAFI. Análises da adoção inicial do IFRS no Brasil. 2011.

Disponível

em:<http://ey.mobi/Publication/vwLUAssets/FIPECAFI_1_ano_de_IFRS/\$FILE /Fipecafi_Baixa.pdf>. Acesso em janeiro de 2012.

Manual de Normas Internacionais de Contabilidade: IFRS versus normas Brasileiras (2 ${ }^{\underline{a}}$ ed.). São Paulo: Atlas, 2010, 415 p. 
FIELDS, T. D.; LYS, T. Z.; VINCENT, L. Empirical research on accounting choice. Journal Of Accounting And Economics, n. 31, p.255-307, 2001. Disponível em: $<$ http://apps.olin.wustl.edu/workingpapers/pdf/2006-06-010.pdf $>$. Acesso em março de 2014.

FRANCIS, J. Discussion of empirical research on accounting choice. Journal of Accounting and Economics, v. 31, p. 309-319, 2001.

GUJARATHY, M. R.; YEZEGEL, A. Spectacular Airlines, Inc.: Implications of the Transition to IFRS in the Context of Cross Border Acquisitions. American Accounting Association, v. 29, n. 1, p. 247-269, 2014a.

GUJARATHY, M. R.; YEZEGEL, A. Teaching Notes Spectacular Airlines, Inc.: Implications of the Transition to IFRS in the Context of Cross-Border Acquisitions. American Accounting Association, v. 29, n. 1, p. 78-93, 2014 b.

HALLER, A.; WEHRFRITZ, M. The impact of national GAAP and accounting traditions on IFRS policy selection - evidence from Germany and the UK. Journal of International Accounting, Auditing and Taxation, v. 22, p. 39-56, 2013.

IUDÍCIBUS, S; MARION, J. C. Introdução à Teoria da Contabilidade. 4. ed. São Paulo: Atlas, 2006. 288 p.

IUDICIBUS, S.; MARTINS, E.; GELBCKE, E. R. Manual de Contabilidade das Sociedades por Ações: aplicável às demais sociedades (Suplemento). 7. ed. São Paulo: Atlas, 2009, 116 p.

LEMES, S.; CARVALHO, L. N. Contabilidade Internacional para Graduação: textos, estudos de casos e questões de múltipla escolha. São Paulo: Atlas, 2010, 232p.

LEMES, S.; COSTA, P. S.; MARTINS, V. A. Efeito na Comparabilidade das Escolhas Contábeis de Empresas Brasileiras no Reconhecimento do Imobilizado. In: XXXVIII EnANPAD 2014, 2014, Rio de Janeiro - RJ. Anais... EnANPAD, 2014.

LORENCINI, F. D.; COSTA, F. M.. Escolhas contábeis no Brasil: identificação das características das companhias que optaram pela manutenção versus baixa dos saldos do ativo diferido. Revista Contabilidade \& Finanças USP, v. 23, n. 58, p. 52-64, 2012.

MULLER, K. A.; RIEDL, E. J.; SELLHORN, T. Causes and Consequences of Choosing Historical Cost versus Fair Value, 2008. Disponível em: 
<http://nd.edu/ carecob/May2008Conference/Papers/RiedlMRS03062008.pdf > Acesso em 26/12/2013.

MURCIA, F. D.; WUERGES, A. Escolhas contábeis no mercado brasileiro: divulgação voluntária de informações versus gerenciamento de resultados. Revista Universo Contábil, Blumenau, v. 7, n. 2, p.28-44, 2011. Disponível em: <http://proxy.furb.br/ojs/index.php/universocontabil/article/view/1878/1597>. Acesso em: março. 2014.

OLIVEIRA, V. A.; LEMES, S. Nível de convergência dos princípios contábeis brasileiros e

norte-americanos às normas do IASB: uma contribuição para a adoção das IFRS por empresas

brasileiras. Revista Contabilidade e Finanças, v. 22, n. 56, p.155-173, 2011.

PRADO, A. G.S.; BATISTA, F.F.; BONOLI, E. L. Avaliação das propriedades para investimento: uma análise dos fatores que influenciam na decisão entre valor justo e modelo de custo. In: CONGRESSO USP DE CONTROLADORIA E CONTABILIDADE, 12, 2012, São Paulo. Anais... São Paulo: USP, 2012, p. 1 - 16. Disponível em: <http://www.congressousp.fipecafi.org/web/artigos122012/618.pdf>. Acesso em: março. 2014.

SILVA, D. M.; MARTINS, V. A.; LEMES, S. Escolhas contábeis: reflexões para a pesquisa no Brasil. In: XXI CONGRESSO BRASILEIRO DE CUSTOS, 21, 2014, NatalRN. Anais... Rio Grande do Norte: CBC, 2014. Disponível em: $<$ http://anaiscbc.emnuvens.com.br/anais/article/view/3801 >.

SOUZA, F. E. A.; SILVA, M. H.; COSTA, P. S. A comparabilidade das escolhas contábeis na avaliação de ativos intangíveis de companhias abertas brasileiras. In: SEMINÁRIOS EM ADMINISTRAÇÃO, 16, 2013, São Paulo. Anais... São Paulo, FEA/USP, 2013.

TAPLIN, R. H. The Measurement of Comparability in Accounting Research. Abacus, v. 47, n. 3, 2011, p. 383-409.

TAPLIN, R. H.; YUAN, W.; BROWN, A. The use of fair value and historical cost accounting for investment properties in China. Australasian Accounting Business and Finance Journal, v. 8, n. 1, p. 101-113, 2014. 
TUDOR, A. T; DRAGU, I. M. Impact of International Financial Reporting Standards on Accounting Practices Harmonization within European Union - Particular Case of Intangible Assets. Annales Universitatis Apulensis Series Oeconomica, v. 12, n. 1, p. 191-206, 2010.

VAN DER TAS, L. G. Measuring Harmonization of Financial Reporting Practice. Accounting and Business Research, v. 18, n. 70, p. 157-169, 1988. 